\title{
KARAKTERISTIK CAMPURAN PANAS ASPHALT CONCRETE WEARING COURSE (AC-WC) MENGGUNAKAN SEMARBUT TIPE 4 SEBAGAI BINDER
}

\author{
Djoko Sarwono ${ }^{1)}$, Djumari ${ }^{2)}$, Trisunan Giri Pamungkas ${ }^{3)}$ \\ 1)23) Roadmate Research Group, Teknik Sipil, Universitas Sebelas Maret \\ Roadmate Research Group, Laboratorium Jalan Raya, Fakultas Teknik, Universitas Sebelas Maret \\ E-mail: sarwono60@yahoo.co.id, djumari.sipil@gmail.com, gicunk1928@gmail.com
}

\begin{abstract}
The current exploiting of asbuton is by extraction. The result of asbuton extraction will be modified with 60/70 penetration grade asphalt binder (SEMARBUT TYPE 4) and used for AC-WC mixture. The AC-WC mixture is a wear coating that is often damaged by vehicle loads and weather, so it is often an improvement on the coating. The frequent improvement in the coating results in increased use of oil asphalt. An $A C$-WC mixture with a Semarbut Type 4 binder is used in the hope of reducing the use of oil asphalt for the improvement of pavement layers. This study aims to determine the value of Marshall Test characteristics and Tensile Strength test from Asphalt Concrete Wearing Course (AC-WC) hot mix using Type 4 Semarbut binder. This research uses experimental method in laboratory. In this study the experiment consists of two phases. The first step is Marshall Test and obtained Marshall Characteristic and Optimum Bitument Content (OBC). The second step is tensile strength testing and obtained value of stress, strain and modulus of elasticity. The results of the analysis were obtained between the specimen with compactor compaction and vibrator compaction having different Marshall characteristic values. The specimen with compactor compaction means the stability, flow, density, and Marshall Quotient values meet the specifications, only VIM values that have not met the specification. The specimen with vibrator compaction means the value of flow and density meets the specification, but the stability, VIM, and Marshall Quotient values do not meet the specification. The tensile strength test obtained the elasticity modulus value of the specimen with compactor and vibrator compaction which has not met the specification. The mixture can not be used for surface layer road pavement.
\end{abstract}

Keywords: AC-WC, Marshall Characteristic, Modulus Elasticity

\begin{abstract}
Abstrak
Pemanfaatan asbuton yang sedang berkembang saat ini adalah dengan cara ekstraksi. Hasil dari ekstraksi asbuton kemudian dimodifikasi dengan aspal minyak penetrasi 60/70 (SEMARBUT TIPE 4) dan digunakan untuk campuran AC-WC. Campuran AC-WC merupakan lapisan aus yang sering mengalami kerusakan akibat beban kendaraan dan cuaca, sehingga sering dilakukan perbaikan pada lapisan tersebut. Seringngya perbaikan pada lapisan tersebut mengakibatkan meningkatnya penggunaan aspal minyak. Campuran AC-WC dengan pengikat Semarbut Tipe 4 digunakan dengan harapan dapat mengurangi penggunaan aspal minyak untuk perbaikan lapis perkerasan jalan. Penelitian ini bertujuan untuk mengetahui nilai karakteristik Marshall Test dan uji kuat tarik dari campuran aspal panas Asphalt Concrete Wearing Course (AC-WC) mengggunakan pengikat Semarbut Tipe 4. Penelitian ini menggunakan metode eksperimental di laboratorium. Pada penelitian ini pengujian terdiri dari dua tahap. Tahap pertama yaitu pengujian Marshall Test dan didapatkan nilai karakteristik Marshall DAN Kadar Aspal Optimum (KAO). Tahap kedua yaitu pengujian kuat tarik dan didapatkan nilai tegangan, regangan dan modulus elastisitas. Hasil analisis didapatkan antara benda uji dengan alat pemadatan compactor dan pemadatan vibrator memiliki nilai karakteristik Marshall yang berbeda. Benda uji dengan alat pemadatan compactor didapatkan nilai stabilitas, flow, kepadatan, dan Marshall Quotient memenuhi spesifikasi, hanya nilai VIM yang belum memenuhi spesifikasi. Sedangkan benda uji dengan alat pemadatan vibrator didapatkan nilai flow dan kepadatan memenuhi spesifikasi, tetapi nilai stabilitas, VIM, dan Marshall Quotient belum memenuhi spesifikasi. Pengujian kuat tarik didapatkan nilai modulus elastisitas dari benda uji dengan alat pemadatan compactor dan vibrator yang belum memenuhi spesifikasi. Campuran belum bisa digunakan untuk lapis permukaan perkerasan jalan.
\end{abstract}

Kata Kunci: AC-WC, Karakteristik Marshall, Modulus Elastisitas

\section{PENDAHULUAN}

Penelitian ini merupakan penelitian lanjutan dari penelitian sebelumnya yang berjudul "Karakteristik Ekstrak Asbuton Emulsi Menggunakan Peremaja Solar yang Dimodifikasi dengan Aspal Penetrasi 60/70 (Semarbut Aspal Tipe 4)". Pada Semabut Tipe 2 didapatkan campuran dengan nilai optimum yaitu 42,5\% ekstraksi asbuton emulsi dan 57,5\% sisanya yaitu aspal minyak penetrasi 60/70. Sedangkan pada Semarbut Tipe 4 didapatkan campuran dengan nilai optimum yaitu 40\% ekstraksi asbuton emulsi dan $60 \%$ sisanya yaitu aspal minyak penetrasi 60/70. Penelitian ini menggunakan campuran Asphalt Concrete Wearing Course (AC-WC). Campuran ACWC merupakan lapisan aus yang sering mengalami kerusakan akibat beban kendaraan dan cuaca, sehingga sering dilakukan perbaikan pada lapisan tersebut. Seringngya perbaikan pada lapisan tersebut mengakibatkan meningkatnya penggunaan aspal minyak. Campuran AC-WC dengan pengikat Semarbut Tipe 4 digunakan 
dengan harapan dapat mengurangi penggunaan aspal minyak untuk perbaikan lapis perkerasan jalan. Penelitian ini bertujuan untuk mengetahui nilai karakteristik Marshall Test dan uji kuat tarik dari campuran aspal panas Asphalt Concrete Wearing Course (AC-WC) mengggunakan pengikat Semarbut Tipe 4. Penelitian ini dilakukan dengan tujuan untuk mengetahui kinerja dari campuran AC-WC menggunakan pengikat Semarbut Tipe 4 dengan pengujian Marshall Test dan pengujian kuat tarik dengan metode kuat tarik tidak langsung (Inderecr Tensile Strength).

\section{TINJAUAN PUSTAKA}

Penelitian tentang "Penelitian Pemanfaatan Asbuton Butir di Kolaka Sulawesi Tenggara" oleh Nyoman Suaryana tahun 2008, diketahui bahwa dari hasil kajian terhadap uji skala penuh di Kolaka Sulawesi Tenggara menunjukkan bahwa asbuton mempunyai kemampuan dapat mensubtitusi aspal minyak serta dapat memperbaiki kinerja campura beraspal.

Penelitian tentang "Tinjauan Karakteristik Marshall dan Kuat Tarik Tidak Langsung Campuran Panas Aspal Beton Menggunakan Semarbut Aspal Tipe I sebagai Binder" oleh Petrich Meysha Buana R tahun 2013, didapat nilai karakteristik Marshall campuran pada Aspal Beton/ Asphalt Concrete (AC) menggunakan Semarbut Aspal Tipe I, yaitu nilai satabilitas campuran sebesar $627,175 \mathrm{~kg}$, nilai densitas sebesar 2,123 gram/cc, nilai porositas sebesar 9,958\%, nilai flow sebesar 2,02 mm, dan nilai Marshall Quotient sebesar 310,483 kg/mm. Nilai karakteristik Marshall seperti stabilitas, densitas, Marshall Quotient (MQ), flow telah memenuhi dengan syarat spesfikasi Aspal Beton/Asphalt Concrete (AC) namun hanya nilai porositas yang tidak memenuhi dengan syarat 3\%-5\%. Analisis kuat tarik tidak langsung diperoleh nilai ITS terkoreksi sebesar 474,407 Kpa, nilai regangan sebesar 0,008002 dan nilai modulus elastisitas sebesar 59614,51. Pada umumnya nilai modulus elastisitas untuk beton aspal sekitar (500$2000 \mathrm{Ksi})(1 \mathrm{Ksi}=6890 \mathrm{Kpa})$. Pada campuran panas Aspal Beton menggunakan Semarbut Tipe I ini, sifat campuran cenderung kaku karena nilai modulus elastsitas masih di bawah syarat modulus elastisitas untuk aspal beton.

Penelitian tentang "Karakteristik Campuran Panas Asphalt Concrete Wearing Course dengan Bahan Pengikat Semarbut Tipe II" oleh Lazuardi Firmansyah Putra (2016), didapatkan nilai stabilitas campuran sebesar 1674,93 kg, nilai kepadatan sebesar 2,836 gram/cc, nilai porositas (VIM) sebesar 4,01\%, nlai flow sebesar 4,6 mm dan nilai Marshall Quotient sebesar 359,074 kg/mm. Nilai kakteristik Marshall seperti stabilitas, Marshall Quotient, flow, dan porositas telah memenuhi batas minimum syarat spesifikasi SNI 03-1737-1989. Sedangkan analisis kuat tarik tidak langsung campuran panas aspal beton menggunakan Semarbut Tipe II, diperoleh nilai kuat tarik tidak langsung terkoreksi sebesar 358,73 Kpa, nilai reegangan 0,0038 dan nilai modulus elastisitas sebesar 13,99 ksi. Pada umumnya nilai modulus elastisitas untuk aspal beton sekitar 500-2000 ksi. Pada campuran panas aspal beton menggunakan Semarbut Tipe II ini, sifat campuran cenderung kaku karena nilai modulus elastisitas masih rendah dan tidak memenuhi syarat modulus elastisitas untuk aspal beton.

\section{DASAR TEORI}

\section{Material Penyusun Campuran Asphalt Concrete Wearing Course (AC-WC) \\ Agregat}

Agregat adalah bahan penyusun utama dalam perkerasan jalan. Mutu dari agregat akan sangat menentukan mutu dari perkerasan yang dihasilkan. Agregat didefinisikan sebagai batu pecah, kerikil, pasir atau komposisi mineral lainnya, baik yang berupa hasil pengolahan (penyaringan, pemecahan). Agregat berperan penting dalam pembentukan lapis perkerasan, dimana daya dukung perkersan jalan ditentukan sebagian besar oleh karakteristik agregat. Pada perkerasan aspal, agregat mengisi 95\% berat campuran atau 75-85\% volume campuran. Agregat dibagi menjadi 3 sesuai ukurannya yaitu agregat kasar (Coarse Agregate), Agregat Halus, dan Filler. Spesifikasi yang digunakan pada campuran panas aspalth concrete wearing course mengacu pada standar SNI 03-1737- 1989. Gradasi yang digunakan yaitu gradasi no. VII yang dapat dilihat pada Tabel 4.

\section{Aspal}

Aspal yang digunakan pada penelitian ini adalah Semarbut Tipe 4. Semarbut Tipe 4 dalah hasil modifikasi antara ekstraksi asbuton emulsi dengan aspal minyak penetrasi 60/70.

Tabel 1. Persyaratan Aspal yang Dimodifikasi dengan Asbuton

\begin{tabular}{cccc}
\hline No & Jenis Pengujian & Metode & Persyaratan \\
\hline 1 & Penetrasi $25^{\circ} \mathrm{C}, 100 \mathrm{gr}, 5$ detik, $0,1 \mathrm{~mm}$ & SNI 06-2456-1991 & $40-60$ \\
\hline
\end{tabular}




\begin{tabular}{cllc}
\hline 2 & Titik Lembek $\left({ }^{\circ} \mathrm{C}\right)$ & SNI 06-2434-1991 & Min. 55 \\
3 & Titik Nyala $\left({ }^{\circ} \mathrm{C}\right)$ & SNI 06-2433-1991 & Min. 225 \\
4 & Daktilitas $25^{\circ} \mathrm{C}, 5 \mathrm{~cm} /$ menit $(\mathrm{cm})$ & SNI 06-2432-1991 & Min. 50 \\
5 & Berat Jenis $(\mathrm{gr} / \mathrm{cc})$ & SNI 06-2441-1991 & Min. 1,0 \\
\hline Sumber: Pemanfaatan Asbuton. Pedoman No: 001 - 01 / BM / 2006, Direktorat Jendral Bina Marga
\end{tabular}

\section{METODELOGI PENEITIAN}

Penelitian ini terdiri atas pengujian Marshall Test dan pengujian kuat tarik tidak langsung dari campuran AC-WC. Sebelumnya dilakukan pengujian karakteristik aspal dari Semarbut Tipe 4. Setelah didapatkan campuran yang optimum, kemudian Semarbut Tipe 4 dicampur dengan agregat untuk dijadikan campuran Asphalt Concrete Wearing Course. Dari pengujian Marshall Test didapatkan nilai-nilai karakteristik Marshall seperti stabilitas, flow, porositas (VIM), kepadatan dan Marshall Quotient. Selain nilai karakteristik Marshall, didapatkan juga nilai kadar aspal optimum yang akan digunakan untuk pembuatan benda uji kuat tarik tidak langsung. Dari pengujian kuat tarik tidak langsung didapatkan nilai tegangan, regangan dan modulus elastisitas. Kemudian kadar aspal optimum juga digunakan untuk pembuatan benda uji dengan alat pemadatan vibrator (15 detik). Benda uji dengan alat pemadat vibrator digunakan untuk pengujian Marshall Test dan uji kuat tarik tidak langsung kemudian hasil pengujian dibandingkn dengan hasil pengujian dengan alat pemadat compactor.

\section{HASIL DAN PEMBAHASAN}

\section{Data Pemeriksaan Agregat}

Pengujian agregat yang dilakukan adalah pengujian berat jenis dan uji keausan dengan menggunakan mesin Los Angles. Hasil pemeriksaan agregat dapat dilihat pada Tabel 2 berikut

Tabel 2. Hasil Pemeriksaan Agregat

\begin{tabular}{clcccc}
\hline No. & \multicolumn{1}{c}{ Jenis Uji } & CA & FA & MA & Spesifikasi \\
\hline 1 & Keausan $(\%)$ & 25,416 & - & - & Maks. 40 \\
2 & Penyerapan $(\%)$ & 1,080 & 2,271 & 1,382 & Maks. 3 \\
3 & Berat Jenis Bulk (gr/cc) & 2,632 & 2,521 & 2,674 & Min. 2,5 \\
4 & Berat Jenis SSD (gr/cc) & 2,661 & 2,578 & 2,684 & Min. 2,5 \\
5 & Berat Jenis Apparent $(\mathrm{gr} / \mathrm{cc})$ & 2,709 & 2,669 & 2,747 & - \\
\hline
\end{tabular}

\section{Data Pengujian Semarbut Tipe 4}

Semarbut Tipe 4 adalah hasil modifikasi antara ekstraksi asbuton emulsi dengan aspal minyak penetrasi 60/70. Pencampuran dilakukan dengan metode panas dingin. Aspal penetrasi 60/70 dipanaskan terlebih dahulu hingga suhu $100^{\circ} \mathrm{C}$, kemudian dicampur dengan ekstraksi asbuton emulsi. Proses pencampuran juga menggunakan alat mixer agar campuran lebih homogen. Dari penelitian sebelumnya didapatkan campuran dengan nilai optimum yaitu 40\% ekstraksi asbuton emulsi dan 60\% sisanya yaitu aspal minyak penetrasi 60/70. Hasil pengujian karakteristik Semarbut Tipe 4 dapat dilihat pada Tabel 3 berikut.

Tabel 3. Hasil Pengujian Karakteristik Semarbut Tipe 4

\begin{tabular}{|c|c|c|}
\hline No. & Jenis Pengujian & Hasil \\
\hline 1 & Penetrasi $\left(\mathrm{x} 10^{-1} \mathrm{~mm}\right)$ & 44 \\
\hline 2 & Daktilitas (cm) & 54 \\
\hline 3 & Titik Lembek $\left({ }^{\circ} \mathrm{C}\right)$ & 55 \\
\hline 4 & Titik Nyala $\left({ }^{\circ} \mathrm{C}\right)$ & 242 \\
\hline 5 & Titik Bakar $\left({ }^{\circ} \mathrm{C}\right)$ & 278 \\
\hline 6 & Berat Jenis ( $\mathrm{gr} / \mathrm{cc}$ ) & 1,23 \\
\hline
\end{tabular}

Sumber: (Dian Putri Rabmawati, 2017)

\section{Data Perencanaan Gradasi}

Perencanaan gradasi campuran AC-WC menggunakan Semarbut Tipe 4 yang digunakan berdasarkan standar SNI 03-1737- 1989. Gradasi yang digunakan adalah gradasi agregat no VII. Data perencanaan gradasi campuran dapat dilihat pada Tabel 4 berikut

Tabel 4. Data Perencanaan Gradasi Campuran

\begin{tabular}{ccc}
\hline No. Saringan & Spesifikasi Campuran No. VII $(\%)$ & Nilai Median $(\%)$ \\
\hline $3 / 4 "$ & 100 & 100 \\
\hline
\end{tabular}




\begin{tabular}{ccc}
\hline $1 / 2 "$ & $80-100$ & 90 \\
$\# 4$ & $54-72$ & 63 \\
$\# 8$ & $42-58$ & 50 \\
$\# 30$ & $26-38$ & 32 \\
$\# 50$ & $18-28$ & 23 \\
$\# 100$ & $12-20$ & 16 \\
$\#$ 200 & $6-20$ & 9 \\
PAN & & \\
\hline
\end{tabular}

Sumber: SNI 03-1737-1989

\section{Data Kadar Aspal Optimum Rencana}

Perencanaan Kadar Aspal Optimum Rencana (Pb) untuk campuran AC-WC menggunakan Semarbut Tipe 4 berdasarkan pada Pedoman Teknik No.028 / T / BM / 1999, dengan persamaan sebagai berikut:

$$
\begin{aligned}
\mathrm{Pb} & =0,035(\% \mathrm{CA})+0,045(\% \mathrm{FA})+0,018(\% \mathrm{FF})+\text { konstanta } \\
\mathrm{Pb} & =0,035(100 \%-\text { lolos saringan no \#8) }+0,045(\text { lolos saringan no \#8 - lolos saringan no \#200) }+0,018 \\
& (\% \text { lolos saringan no \#200) + konstanta } \\
\mathrm{Pb} & =0,035 \times(100-50)+0,045 \times(50-9)+0,018 \times(9)+1 \\
& =6,215 \% \sim 6 \%
\end{aligned}
$$

dimana: $\quad \mathrm{CA}=$ Agregat kasar

$\mathrm{FA}=$ Agregat halus

$\mathrm{FF}=$ Bahan pengisi

Dari perhitungan di atas, diperoleh kadar aspal Semarbut Tipe 4 yang akan digunakan yaitu berkisar antara 5\%$7 \%$.

\section{Hasil Uji Volumentrik Benda Uji Marshall Test}

Uji volumentrik bertujuan untuk mendapatkan nilai kepadatan, VIM, VFB, dan VMA. Hasil perhitungan Volumentrik benda uji dapat dilihat pada Tabel 5 berikut.

Tabel 5. Hasil Perhitungan Volumentrik Benda Uji

\begin{tabular}{ccccccc}
\hline $\begin{array}{c}\text { Kode Benda } \\
\text { Uji }\end{array}$ & $\begin{array}{c}\text { Kadar } \\
\text { Semarbut } \\
\text { Tipe IV }(\%)\end{array}$ & $\begin{array}{c}\text { Koreksi } \\
\text { Tebal } \\
(\mathrm{cm})\end{array}$ & $\begin{array}{c}\text { Kepadatan } \\
\text { (gr/cc) }\end{array}$ & VMA (\%) & VIM (\%) & VFB (\%) \\
\hline 5A & 5 & 0,918 & 2,3 & 14,6 & 8,7 & 52,6 \\
5B & 5 & 0,927 & 2,3 & 14,8 & 8,9 & 51,7 \\
5C & 5 & 0,920 & 2,3 & 14,9 & 9,1 & 51,0 \\
Rata-Rata & 5 & 0,921 & 2,3 & 14,8 & 8,9 & 51,8 \\
5,5A & 5,5 & 0,913 & 2,3 & 14,2 & 7,2 & 61,4 \\
5,5B & 5,5 & 0,915 & 2,3 & 14,1 & 7,2 & 61,8 \\
5,5C & 5,5 & 0,927 & 2,4 & 13,6 & 6,7 & 64,2 \\
Rata-Rata & 5,5 & 0,918 & 2,3 & 14,0 & 7,0 & 62,4 \\
6A & 6 & 0,901 & 2,4 & 12,9 & 4,9 & 76,2 \\
6B & 6 & 0,898 & 2,4 & 12,8 & 4,8 & 76,9 \\
6C & 6 & 0,916 & 2,4 & 12,9 & 4,9 & 76,3 \\
Rata-Rata & 6 & 0,905 & 2,4 & 12,9 & 4,8 & 76,5 \\
6,5A & 6,5 & 0,911 & 2,4 & 13,8 & 4,7 & 78,2 \\
6,5B & 6,5 & 0,921 & 2,4 & 13,6 & 4,6 & 79,2 \\
6,5C & 6,5 & 0,911 & 2,4 & 13,8 & 4,9 & 78,8 \\
Rata-Rata & 6,5 & 0,914 & 2,4 & 13,7 & 4,7 & 78,4 \\
7A & 7 & 0,920 & 2,4 & 14,3 & 4,4 & 81,8 \\
7B & 7 & 0,928 & 2,4 & 14,1 & 4,1 & 83,3 \\
7C & 7 & 0,924 & 2,4 & 14,3 & 4,3 & 82,1 \\
Rata-Rata & 7 & 0,924 & 2,4 & 14,3 & 4,3 & 82,4 \\
\hline
\end{tabular}

\section{Hasil Uji Marshall Test}

Pengujian Marshall Test berdasarkan dengan RSNI M-01-2003 tentang Metode Pengujian Campuran Beraspal Panas dengan Alat Marshall. Hasil dari pengujian Marshall Test dapat dilihat pada Tabel 6 sebagai berikut:

Tabel 6. Rekapitulasi Analisis Data Pengujian Marshall Test 


\begin{tabular}{ccccccc}
\hline Sifat & \multicolumn{5}{c}{ Kadar Semarbut Tipe IV } & \multicolumn{2}{c}{ Standar SNI } \\
Campuran & $5 \%$ & $5,5 \%$ & $6 \%$ & $6,5 \%$ & $7 \%$ & \\
\hline Stabilitas (kg) & 1234,8 & 1358,1 & 1431,5 & 1372,6 & 1305,9 & Min. 550 \\
Flow $(\mathrm{mm})$ & 3 & 3,37 & 4,2 & 4,4 & 4,5 & $2,0-4,0$ \\
MQ $(\mathrm{kg} / \mathrm{mm})$ & 412,1 & 406,1 & 341,8 & 313,8 & 291,2 & $\begin{array}{c}\text { Min. } 200 \\
\text { Maks. 350 }\end{array}$ \\
Kepadatan & 2,3 & 2,3 & 2,4 & 2,4 & 2,4 & $2-3$ \\
(gr/cc) & & & & & & $3-5$ \\
VIM (\%) & 8,984 & 7,028 & 4,838 & 4,755 & 4,283 & Min. 78 \\
VFB (\%) & 51,8 & 62,4 & 76,5 & 78,4 & 82,4 & Maks. 82 \\
\hline
\end{tabular}

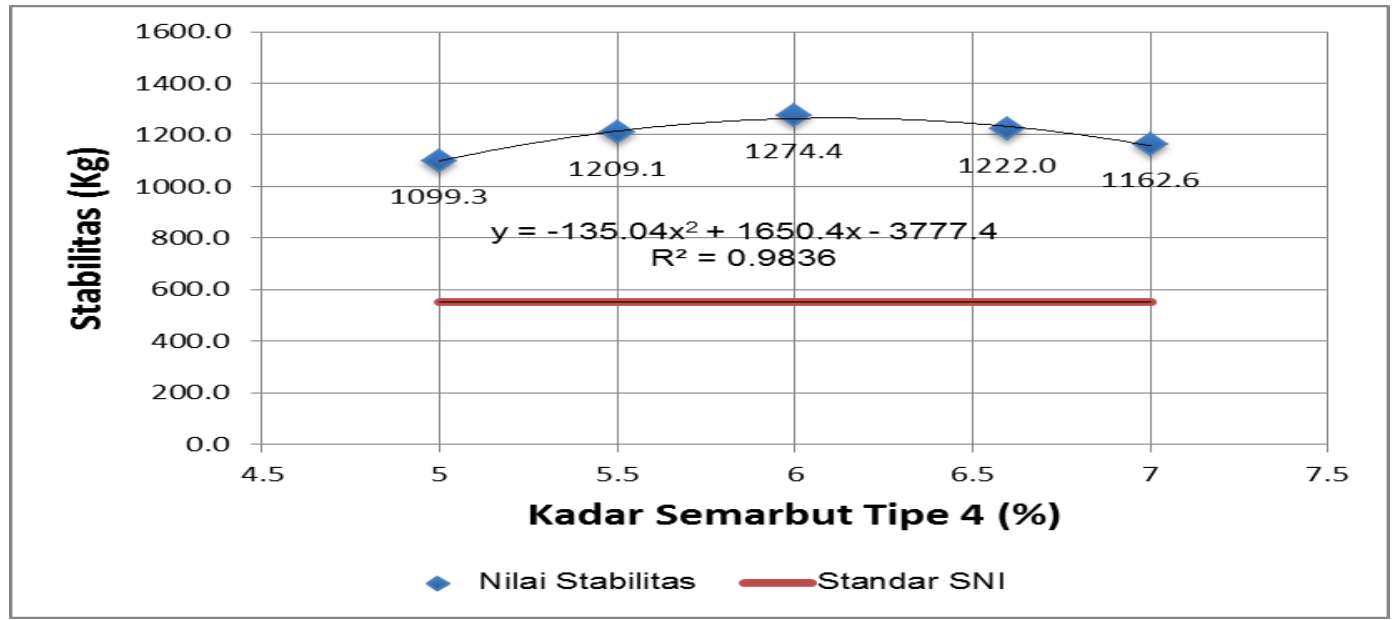

Gambar 1. Grafik Hubungan Kadar Semarbut Tipe 4 dengan Stabilitas

Gambar 1 di atas menunjukkan peningkatan stabilitas hingga pada tingkat optimum pada kadar 6\% yang kemudian stabilitas mengalami penurunan sesuai dengan penambahan kadar aspal.

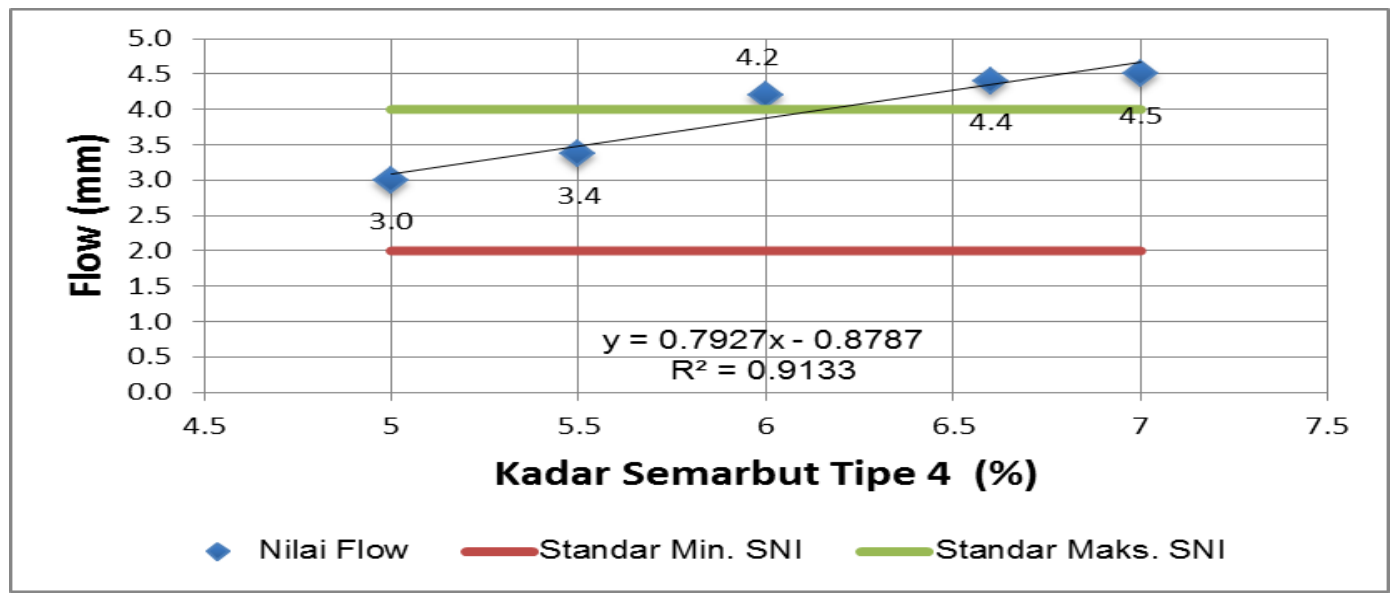

Gambar 2. Grafik Hubungan Kadar Semarbut Tipe 4 dengan Flow

Gambar 2. di atas menunjukkan nilai Flow mengalami kenaikan seiring dengan penambahan kadar aspal. Nilai Flow yang semakin besar menunjukan bahwa campuran bersifat plastis. Rongga aspal yang semakin besar membuat rentang kelelahan aspal semakin besar, sehingga benda uji lebih mampu mengikuti perubahan bentuk sampai benda uji tersebut hancur karena pembebanan. Sedangkan semakin kecil nilai Flow maka campuran sangat potensial mengalami keretakan. 


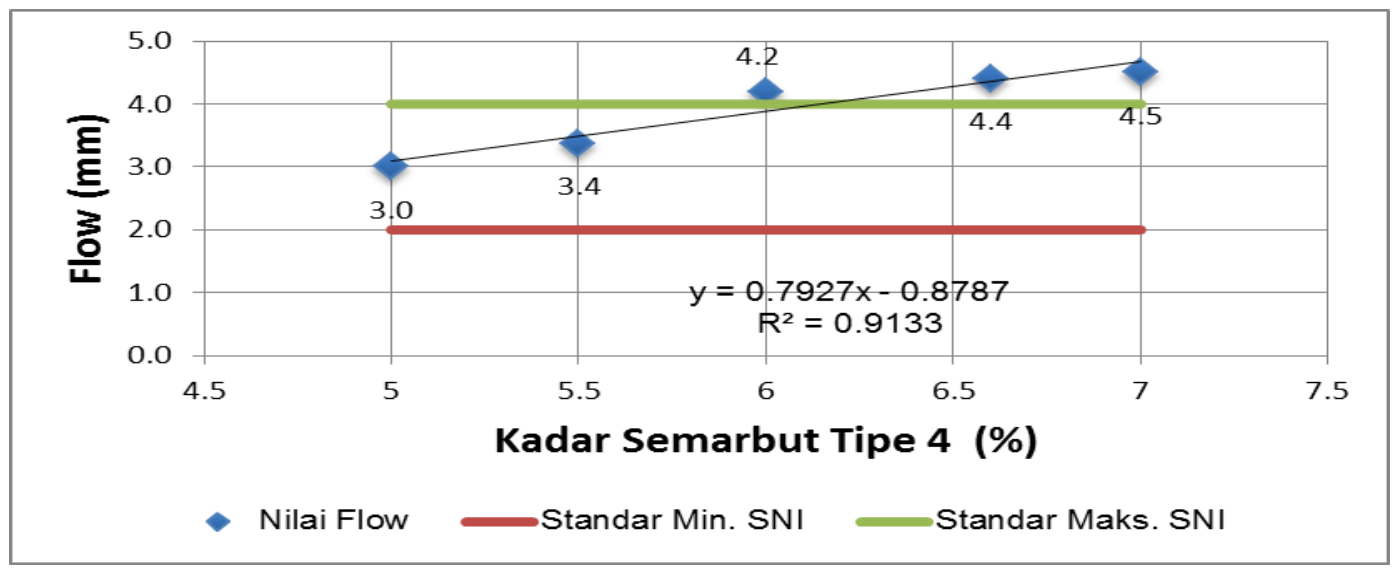

Gambar 3. Grafik Hubungan Kadar Semarbut Tipe 4 dengan Marshall Quoient

Gambar 3 di atas menunjukkan nilai Marshall Quotient mengalami penurunan seiring dengan penambahan kadar aspal. Marshall Qoutient merupakan pendekatan terhadap tingkat kekakuan dan fleksibilitas campuran. Semakin besar nilai Marshall Quotient berarti semakin kaku dan sebaliknya semakin kecil nilai Marshall Qoutient maka perkerasannya semakin lentur. Akan tetapi jika nilai Marshall Quotient terlalu rendah, maka campuran aspal ini akan mudah mengalami perubahan bentuk akibat beban kendaraan.

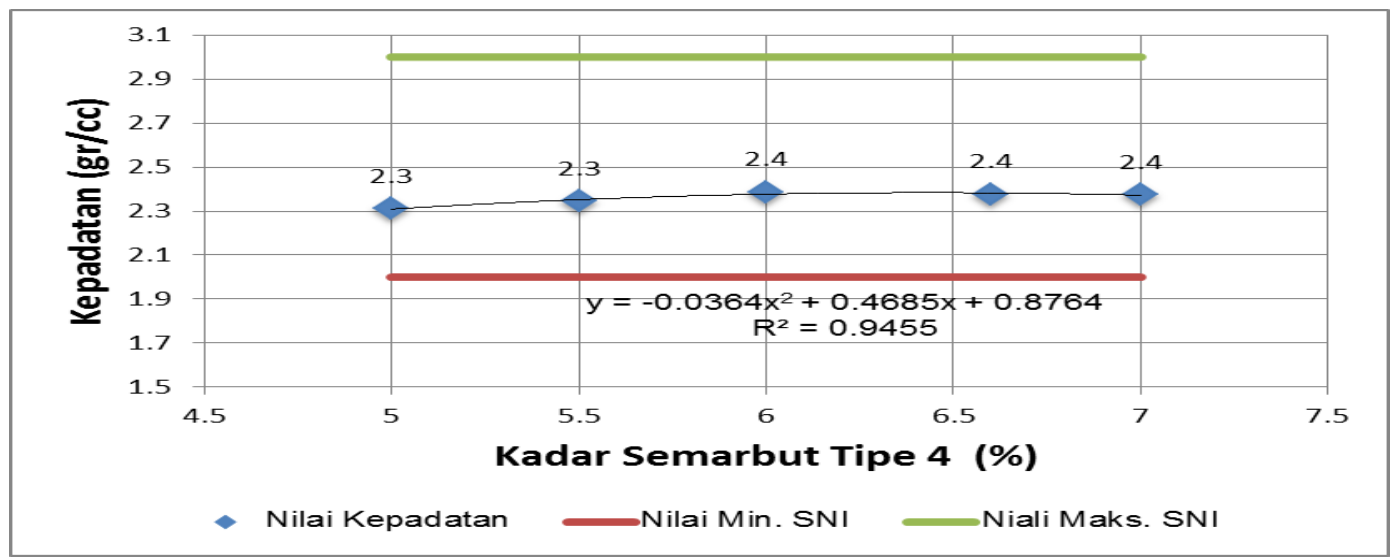

Gambar 4. Grafik Hubungan Kadar Semarbut Tipe 4 dengan Kepadatan

Gambar 4. di atas menunjukkan bahwa kadar aspal mempengaruhi nilai kepadatan. Hal ini dipengaruhi olah beberapa faktor seperti gradasi agregat, kadar aspal, berat jenis agregat, dan proses pemadatan yang meliputi suhu serta jumlah tumbukannya. Semakin padat campuran semakin tinggi pengikatan antara partikel, baik dari agregat maupun dari lapisan aspal itu sendiri. Hal ini disebabkan karena bahan pengisi (filler) mempunyai butiran lebih halus yang mengakibatkan lebih mudah bercampur dengan aspal membentuk campuran yang memiliki viskositas lebih rendah. Campuran yang memiliki nilai kepadatan akan mampu menahan beban yang lebih besar jika dibandingkan dengan campuran yang memiliki kepadatan rendah. 


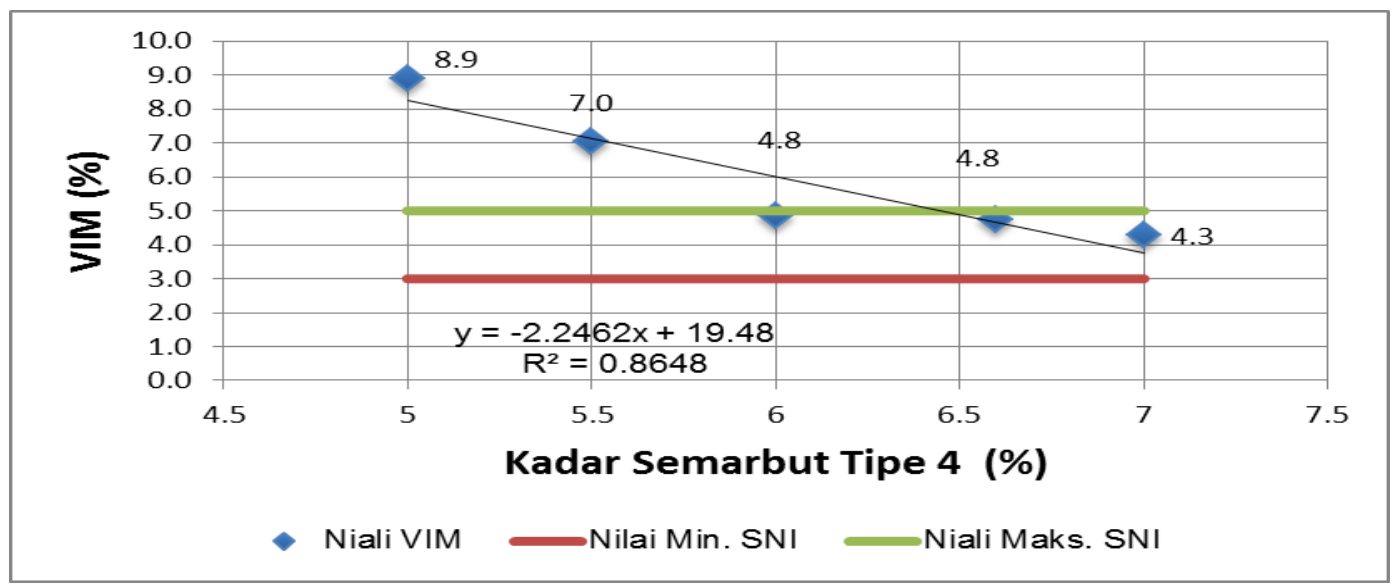

Gambar 5. Grafik Hubungan Kadar Semarbut Tipe 4 dengan VIM

Gambar 5 di atas menujukkan nilai VIM mengalami penurunan seiring dengan penambahan kadar aspal. Hal ini dipengaruhi oleh gradasi agregat, kadar aspal, kepadatan dan proses penumbukan campuran. Berdasarkan grafik di atas, nilai VIM yang tinggi dikarenakan masih terdapat rongga yang besar di dalam campuran. Tingginya nilai VIM dapat menyebabkan mudahnya air dan udara masuk ke dalam lapisan perkerasan sehingga dapat mengurangi keawetan pada lapisan perkerasan. Sedangkan rendahnya nilai VIM pada campuran dapat menyebabkan terjadinya bleeding karena penggunaan aspal yang terlalu banyak.

\section{Analisis Kadar Aspal Optimum}

Nilai kadar aspal optimum dihitung dengan persamaan regresi hubungan antara kadar aspal dengan nilai stabilitas sebagai berikut:

$$
\begin{array}{ll}
\mathrm{y}, & =-135,04 \mathrm{x}^{2}+1650,4 \mathrm{x}-3777,4 \\
\mathrm{y}^{\prime} & =0 \\
\mathrm{y}^{\prime} & =-270,08 \mathrm{x}+1650,4 \\
\mathrm{y}, & =6,11 \%
\end{array}
$$

\section{Hasil Uji Kuat Tarik Tidak Langsung}

Metode yang digunakan adalah kuat tarik tidak langsung (Inderecr Tensile Strength). Pembuatan benda uji sama dengan pembuatan benda uji Marshall Test, hanya saja kadar aspal yang digunakan adalah kadar aspal optimum. Hasil pengujian dapat dilihat sebagai berikut.

Tabel 9. Rekapitulasi Hasil Pengujian Kuat Tarik Tidak Langsung

\begin{tabular}{cccc}
\hline Kode Benda Uji & Regangan & ITS (Tegangan) $(\mathrm{KPa})$ & Modulus Elastisitas (Ksi) \\
\hline A & 0,0080 & $1.131,10$ & 20,56 \\
B & 0,0083 & $1.143,57$ & 19,92 \\
C & 0,0083 & $1.160,95$ & 20,22 \\
Rata-Rata & 0,0082 & $1.145,21$ & 20,23 \\
\hline
\end{tabular}

\section{Pembahasan Uji Kuat Tarik Tidak Langsung}

Modulus elastisitas adalah perbandingan antara nilai tegangan dan regangan campuran. Modulus elastisitas merupakan ukuran kekakuan dari suatu bahan. Bila nilai modulus elastisitas tinggi, maka perubahan bentuk yang terjadi akibat gaya yang diberikan semakin sedikit. Berdasarkan hasil perhitungan modulus elastistas diatas, sifat dari campuran panas AC-WC menggunakan Semarbut Tipe 4 kurang elastis. Nilai rata-rata yang didapatkan sebesar 20,23 Ksi yang mana pada umumnya nilai modulus elastisitas untuk aspal beton sekitar 500-2000 Ksi.

\section{Pembuatan Benda Uji Pemadatan Alat Vibrator}

Benda uji dengan alat pemadat vibrator dibuat menggunakan cetakan plat yang kemudian benda uji diambil menggunakan alat core drill. Benda uji digunakan untuk Marshall Test dan Uji Kuat Tarik Tidak langsung. Hasil analisis data didapatkan rekapitulasi sifat campuran yang dapat dilihat pada Tabel 10 dan Tabel 11 berikut. 
Tabel 10. Rekapitulasi Perbandingan Analisis Data Pengujian Marshall Test

\begin{tabular}{lccc}
\hline \multicolumn{1}{c}{ Sifat Campuran } & \multicolumn{2}{c}{ Benda Uji Pemadatan } & Standar SNI \\
& Alat Compactor & Alat Vibrator & \\
\hline Stabilitas (kg) & 1265,2 & 505,1 & Min. 550 \\
Flow $(\mathrm{mm})$ & 4,0 & 3,8 & $2,0-4,0$ \\
MQ $(\mathrm{kg} / \mathrm{mm})$ & 309,2 & 135,3 & Min. 200, Maks. 350 \\
Kepadatan $(\mathrm{gr} / \mathrm{cc})$ & 2,4 & 2,2 & $2-3$ \\
VIM $(\%)$ & 5,7 & 12,4 & $3-5$ \\
VFB $(\%)$ & 72,0 & 46,5 & Min. 78, Maks. 82 \\
\hline
\end{tabular}

Tabel 11. Rekapitulasi Perbandingan Analisis Data Pengujian Kuat Tarik Tidak Langsung

\begin{tabular}{lcc}
\hline \multicolumn{1}{c}{ Sifat Campuran } & \multicolumn{2}{c}{ Benda Uji Pemdatan } \\
& Alat Compactor & Alat Vibrator \\
\hline Regangan & 0,008 & 0,013 \\
Tegangan $(\mathrm{KPa})$ & $1.145,21$ & 509,98 \\
Modulus Elastisitas $(\mathrm{ksi})$ & 20,23 & 5,56 \\
\hline
\end{tabular}

Berdasarkan tabel diatas, dapat dilihat bahwa karakteristik Marshall dan Karakteristik kuat tarik yang dihasilkan antara benda uji dengan alat pemadat compactor dengan benda uji alat pemadat vibrator memiliki nilai yang berbeda.. Hal ini dapat disebabkan oleh proses pemadatan yang berbeda. Pemadatan menggunakan compactor lebih menyeluruh di penampang mould dan jumlah tumbukan yang banyak sehingga pemadatan lebih sempurna, sedangkan pemadatan menggunakan alat pemadat vibrator dilakukan per titik. Hal ini menyebabkan tidak terkontrolnya suhu di setiap titik, penguncian antar agrgeat yang tidak optimal, dan kepadatan yang kurang di tiap titiknya.

\section{SIMPULAN}

Hasil analisis didapatkan antara benda uji dengan alat pemadatan compactor dan pemadatan vibrator memiliki nilai karakteristik Marshall yang berbeda. Benda uji dengan alat pemadatan compactor didapatkan nilai stabilitas, flow, kepadatan, dan Marshall Quotient memenuhi spesifikasi, hanya nilai VIM yang belum memenuhi spesifikasi. Sedangkan benda uji dengan alat pemadatan vibrator didapatkan nilai flow dan kepadatan memenuhi spesifikasi, tetapi nilai stabilitas, VIM, dan Marshall Quotient belum memenuhi spesifikasi. Pengujian kuat tarik didapatkan nilai modulus elastisitas dari benda uji dengan alat pemadatan compactor dan vibrator yang belum memenuhi spesifikasi. Campuran belum bisa digunakan untuk lapis permukaan perkerasan jalan.

\section{REKOMENDASI}

1. Penelitian lebih lanjut disarankan menggunakan jenis campuran lain agar dapat diketahui karakteristik tiap campuran bila menggunakan bahan pengikat yang sama.

2. Penelitian lebih lanjut terhadap bahan pengikat yang digunakan sangat disarankan agar dapat meningkatkan kinerja campuran.

3. Penelitian lebih lanjut disarankan menggunakan alat pemadat vibrator yang mudah digerakkan sehinga pemadatan lebih merata dan suhu dapat terkontrol.

\section{REFERENSI}

Direktorat Jendral Bina Marga. 2006. Pemanfaatan Asbuton. Pedoman No: 001 - 01 / BM / 2006. Jakarta: Kementrian Pekerjaan Umum

Direktorat Jendral Bina Marga. 2006. Pemanfaatan Asbuton. Pedoman No: 001 - 05 / BM / 2006. Jakarta: Kementrian Pekerjaan Umum

Putra, Lazuardi Firmansyah. 2016. Karakteristik Campuran Panas Asphalt Concrete Wearing Course Menggunakan Pengikat Semarbut Tipe II (Modifikasi Aspal Minyak Penetrasi 60/70 dengan Ekstraksi Asbuton Emulsi). Surakarta: Universitas Sebelas Maret

Richiantoro, Petrich M B. 2013. Tinjauan Karakteristik Marshall dan Kuat Tarik Tidak Langsung Campuran Panas Aspal Beton Menggunakan Semarbut Aspal Tipe I sebagai Binder. Surakarta: Universitas Sebelas Maret

Sukirman, Silvia (2003). Beton Aspal Campuran Panas.Jakarta: Yayasan Obor Indonesia 
Suryana, Nyoman. 2008. Pemanfaatan Asbuton Butir di Kolaka Sulawesi Tenggara. Bandung: Badan Litbang Departemen Pekerjaan Umum

Sutrisna, Puja. 2013. Perbandingan Karakteristik Marshall Asbuton Modifikasi dengan Aspal Penetrasi 60/70 pada Campuran Asphalt Concrete - Wearing Course (AC-WC). Lampung: Universitas Lampung

Wibowo, Luqman Try. 2016. Karakteristik. Penambahan Ekstraksi Asbuton Emulsi pada Aspal Penetrasi 60/70 sebagai Modifikasi Bitumen (Semarbut Tipe 2). Surakarta: Universitas Sebelas Maret 